Jeffrey, P.: Personal space in a virtual community. In: Carat, C.M., Lund, A. (eds.). Summary of the Conference on Human Factors in Human Factors in Computing Systems (CHI '98), April 18-23 1998, Los Angeles. New York, NY: ACM, 1998, 347-348. Student Poster.

\title{
Personal Space in a Virtual Community
}

\author{
Phillip Jeffrey \\ GMD - German National Research Center for Information Technology \\ FIT - Institute for Applied Information Technology \\ 53754 Sankt Augustin, Germany \\ E-mail: Phillip.Jeffrey@gmd.de
}

\begin{abstract}
This paper explores whether the societal norm of personal space influences behaviour during interaction and communication in a virtual environment. An online virtual world was explored using a participatory-observer approach over a period of 3 months. The results parallel personal space and physical distance literature: personal space exists; influences behaviour; produces discomfort and possible flight when violated. Future research should explore whether these results indicate identification with one's avatar or another influence.
\end{abstract}

\section{Keywords}

Virtual community, avatars, personal space

\section{INTRODUCTION}

Personal space may be defined as an invisible area surrounding an individual which functions as a buffered comfort zone during interpersonal interaction $[3,9,11]$. Proxemics, the study of people's personal space [5], focuses on societal norms, comfortable interpersonal distances and self-protection from violations. Hall, its originator, shows that one's preferred distance for comfortable communication has societal (contact vs. non-contact), social (stranger vs. friend) and conversational intimacy (business vs. casual) determinants $[5,6,7]$.
Within physical environments, guidelines outlining appropriate behaviour and societal norms regulate individual behaviour during social interaction [10]. Spatial invasions, societal norm violations of personal space, occur when an individual unexpectedly or undesirably enters another's personal space [12]. Felipe \& Sommer [4] suggest that these invasions produce signs of discomfort prior to eventual flight. Also, stressful reactions to personal space invasions have been demonstrated within crowds [13], as well as for individuals [7]. Therefore, much evidence has shown the existence of personal space behaviours within natural environments, which suggest that a comfortable distance for communication exists [e.g. 2, 4, 9].

\section{RESEARCH GOAL}

Does the societal norm of personal space influence behaviour during interaction and communication in a virtual world? If personal space exists in a shared virtual environment, I am interested in how it is expressed. This paper is part of a larger research study that investigates the attributes and conventions that correspond between the physical and virtual world. In this paper, I investigate the societal norm of personal space in order to examine what aspects may be transferred into a virtual world. Are individuals during virtual interaction aware of personal space, and do they adjust their behaviour to maintain a comfortable personal distance for interpersonal communication? 


\section{METHODOLOGICAL RESEARCH SETTING}

APPROACH AND

In this study, the effect of personal space is reported from ethnographic research of an on-line virtual environment, using a qualitative, participatory-observer approach. Active Worlds ${ }^{1}$ (AW) is a graphical 3D world with graphical 3D representations that is accessible from the internet and offers different types of avatars, modes of transportation, and homes to build. Avatars communicate, socialise, and interact with other avatars. The basic functionality available for the representations and communication is:

- full-bodied avatars can walk and exhibit movements of waving, jumping, and dancing, activated by mouseclicks. Avatars can move in three dimensions by using the arrow keys. Communication between people is text-based by typing on the keyboard. All public messages appear in a scrollable window and also above the avatar's head with the avatar's name for 30 seconds or until the next typed message appears.

- methods of transportation include: walking using the arrow keys for navigation; flying using the addition key $(+)$ initially, followed by the arrow keys; and teleporting between two points by typing in the desired end-co-ordinates.

The author spent about 25 hours observing AW between the months of September and November, 1997. On-line recording and logging were not performed due to privacy concerns.

To investigate personal distance, I was interested to what extent the notion of space in the physical environment, and the corresponding behavioural expectations [8], transfer into a virtual environment. The following behaviours were coded: 1) Does a social distance exist during conversations? 2) What happens when this distance is violated?

\section{RESULTS}

The following are the main results found from the observation:

\footnotetext{
${ }^{1}$ Copyright $(0)$ 1995-1998 Circle of Fire, Inc.
}

- avatars maintained a distinct social distance between themselves in face-to-face conversation that increased as group size increased

- when additional members joined a group, group members repositioned themselves, expanding the social space and relative personal space of the group.

- group size determined group shape: two avatars formed a line; three, a triangle; four, a diamond; and larger groups adopted a circle-shaped form.

- invasions of personal space occurred when the Observer (O) moved from a pre-existing social distance during his conversation and repositioned his avatar face-to-face in extreme close proximity to another avatar causing discomfort reactions.

The following are some examples which illustrate the results:

- example 1: O met Laracat in the AlphaWorld supply dock getting building materials. O moved face-to-face eliminating the pre-existing social distance. Immediately, Laracat moved back maintaining a slightly larger distance than had been previously observed. Her verbal response confirmed discomfort. She spoke about preferring face-to-face conversations and about feeling uncomfortable with avatars "too close" to her face.

Laracat: actually...It's funny...but it does make me uncomfortable when another avatar gets "too close" in my avatar's face.

Mango[avatar name of O]: why?

Laracat: [moves back] just does

Laracat: This is a nice distance to keep.....:)

Laracat: [I backed up] the same way I'd back up if a "real" person got up that close....someone I don't know very well 
- example 2: after conversing about turn-taking signals conveyed during conversations in the Ground Zero courtyard of AlphaWorld, the landing point when entering the world, $\mathrm{O}$ moved face-to-face eliminating a previous comfortable social distance. Twice, Spike G moved back two steps and twice $\mathrm{O}$ removed the existing social distance. His verbal response confirmed discomfort.

\section{Moon [avatar name of $\mathrm{O}]$ : Is this too close.. (-) \\ Spike G: [moved back] hahaha \\ Spike G: Moon I can't breathe \\ Spike G: I hardly know you \\ Spike G: Moon...ppl [people] will see you....cut that out \\ Spike G: *blushing* \\ Spike G: [to everyone] Moon is...um....naked and....well....touching me basically...}

In $\mathrm{AW}$, the text above the avatars overlaps when the avatars are too close, but text also appears in the window below. The comments suggest that it is not the text overlap that people are annoyed about since their comments have more to do with one's personal space being violated.

- example 3: In America, O first observed Wicca and then spoke with her in the Ground Zero courtyard. He then repositioned his avatar face-to-face eliminating the pre-existing distance. Wicca indicated being unaffected by the personal space invasion, but her behaviour changed as she moved back to re-establish a social distance.

Wicca: doesn't bother me in here, just in real life

- example 4: After conversing with Drew21 in AlphaWorld for a few minutes about similarities between the real world and the virtual world, $\mathrm{O}$ moved face-to-face removing the pre-existing social distance. Drew21's verbal response and behaviour confirmed being aware but unaffected by the personal space violation as the avatars remained in close proximity for the duration of the conversation.
Drew21: no, not bothered, we have been talking for a few minutes, so I know you are not getting in my face

\section{DISCUSSION}

My research goal was to investigate if personal space influences behaviour within a virtual world. The results showed that many people expressed discomfort when the observer's avatar was positioned too close, which suggests the existence of personal space. Individuals created a social distance during interpersonal communication and avoided violating another person's personal space. Spatial invasions produced anxiety-arousing behaviour with attempts to re-establish a preferred social distance, similar to physical world observations.

Future areas of research should examine more closely whether the concept of personal space, transferred into a virtual environment, suggests the identification with one's avatar, or if another explanation might exist.

\section{ACKNOWLEDGEMENTS}

This research is part of the Social Web project at the GMD FIT. I would like to thank Gloria Mark for her useful comments and valuable assistance. I would also like to acknowledge the input provided by the anonymous reviewers.

\section{REFERENCES}

1. Active Worlds. http://www.activeworlds.com.

2. Baxter, J.C. (1970). Interpersonal spacing in natural settings. Sociometry. 33, 444-456.

3. Dosey, M.A. \& Meisels, M. (1969). Personal space and self-protection. Journal of Personality and Social Psychology. 11, 93-97.

4. Felipe, N.J. \& Sommer, R. (1966). Invasions of personal space. Social Problems. 14, 206-214.

5. Hall, E.T. (1963). A system for the notation of proxemic behavior. American Anthropologist. 65, 1003-1026.

6. Hall, E.T. (1966). The Hidden Dimension. New York: Doubleday.

7. Hall, E.T. (1973). The Silent Language. Garden City: Anchor Press.

8. Harrison, S. \& Dourish, P. (1996). Re-Place-ing Space: The roles of place and 
space in collaborative systems. In $\mathrm{M}$. Ackerman, (ed). Proc. of the ACM 1996 Conference on CSCW, Nov. 16-20, 1996, Boston, MA.

9. Hayduk, L.A. (1978). Personal space: An evaluative and orienting overview. Psychological Bulletin. 85, 117-134.

10.Jandt, F.E. (1995). Intercultural Communication. Thousand Oaks: Sage.
11.Little, K.B. (1965). Personal space. Journal of Experimental Social Psychology, 1, 237-247.

12.Sundstrom, E., \& Altman, I. (1976). Interpersonal relationships and personal space: Research review and theoretical model. Human Ecology. 4, 47-67.

13.Worchel, S. \& Teddlie, C. (1976). The experience of crowding: A two factor theory. Journal of Personality and Social Distance. 34, 30-40. 